\title{
Peningkatan Mutu melalui Implementasi Manajemen PAKIS
}

\author{
Rismayani ${ }^{1}$; Nurhayati ${ }^{2}$ \\ ${ }^{1}$ Guru SD Negeri 6 Kota Langsa \\ ${ }^{2}$ Pengawas SD Dinas Pendidikan dan Kebudayaan Kota Langsa \\ rismayanispdi78@gmail.com
}

\begin{abstract}
The problem of school quality is a classic problem that until now has encountered obstacles in the field. The various school management models that have been implemented sometimes do not match the character of the school and the conditions of the school. So in this school action research, it is tried to apply the PAKIS management model to improve the quality of the school in question. The purpose of this study was to reveal the impact of implementing PAKIS management with all its supporting factors at SD Negeri 6 Langsa City. This study uses the School Action Research (PTS) method by involving the Principal as a researcher, Teachers, Education Personnel, Students and parents of students and stakeholders. Data obtained through observation and interviews and then analyzed using the PTS step. This study concludes that the implementation of PAKIS management at SD Negeri 6 Langsa City is going well, the perceived impact of implementing PAKIS management can improve school achievement at SD Negeri 6 Langsa including: Increasing student achievement in both curricular and non-curricular fields, teacher achievement, achievement school and principal's performance. Supporting factors for implementing PAKIS school-based management in improving school achievement include support from school residents, community support and support from other institutions.
\end{abstract}

Keywords: Quality Improvement, PAKIS Management and Principal Performance.

\begin{abstract}
Abstrak
Permasalahan mutu sekolah merupakan permasalahan klasik yang sampai saat ini menemui kendala di lapangan. Berbagai model manajemen sekolah yang telah diterapkan terkadang tidak sesuai dengan karakter sekolah dan kondisi sekolah. Maka pada penelitian tindakan sekolah ini dicoba menerapkan model manajemen PAKIS untuk meningkatkan mutu sekolah yang dimaksud. Tujuan penelitian ini adalah untuk mengungkapkan dampak dari penerapan manajemen PAKIS dengan segala faktor pendukungnya di SD Negeri 6 Kota Langsa. penelitian ini menggunakan metode Penelitian Tindakan Sekolah (PTS) dengan melibatkan Kepala Sekolah selaku peneliti, Guru, Tenaga Kependidikan, Siswa dan orang tua siswa serta pemangku kepentingan. Data diperoleh melalui observasi dan wawancara kemudian dianalisis dengan menggunakan langkah PTS. Penelitian ini memperoleh kesimpulan bahwa pelaksanaan mananemen PAKIS di SD Negeri 6 Kota Langsa berjalan dengan baik, dampak yang dirasakan dari penerapan manajemen PAKIS dapat meningkatkan prestasi sekolah di SD Negeri 6 Langsa diantaranya: Peningkatan prestasi siswa baik dalam bidang kurikuler maupun nonkurikuler, prestasi guru, prestasi sekolah maupun prestasi kepala sekolah. Faktor pendukung pada penerapan manajemen berbasis sekolah PAKIS dalam meningkatkan prestasi sekolah di antaranya dukungan warga sekolah, dukungan masyarakat dan dukungan lembaga lain.
\end{abstract}

Kata Kunci: Peningkatan Mutu, Manajemen PAKIS dan Kinerja Kepala Sekolah. 


\section{A. Pendahuluan}

Mutu pendidikan berkaitan erat dan sangat dipengaruhi oleh manajemen kepala sekolah (Nurkuntari 2016). Dalam rangka menjamin mutu pendidikan secara terus-menerus maka seorang kepala sekolah mesti memiliki kemampuan manajerial yang baik (Puspitasari, Tobari, and Kesumawati 2020). Memimpin sekolah tentunya berbeda dengan memimpin perusahaan ataupun organisasi lainnya. Karena kepala sekolah haruslah memiliki kemampuan mendidik, kemampuan pedagogi, kompetensi sosial, menciptakan iklim belajar yang nyaman, mewujudkan tata tertib sekolah dan mampu menunjukkan keteladanan di kalangan sekolah dan masyarakat pada umumnya. Maka dalam hal ini kepala sekolah berperan sebagai edukator, manajer, administrator, supervisor, leader, inovator, dan motivator (Sari 2018). Sependapat dengan yang dikatakan oleh Muzakar (2014) bahwa kepala sekolah berperan penting sebagai pendidik, manajer, administrator, supervisor, leader dan innovator.Oleh karena itu, kepala sekolah harus menggunakan strategi yang tepat agar mutu dan arah kemajuan pendidikan dapat dicapai (Adam, Kuriady, and Komariah 2018).

Mutu pendidikan yang dituangkan dalam Standar Nasional Pendidikan merupakan suatu kewajiban mutlak bagi kepala sekolah untuk menjalankannya (Alawiyah 2017). Dalam rangka pencapaian standar nasional pendidikan, kelayakan sekolah dapat ditinjau dari segi aspek performance yaitu mutu lulusan, mutu guru, proses pembelajaran dan manajemen sekolah. Aspek tersebut dapat mewakili untuk menilai kelayakan apakah suatu program dan lembaga sudah bersinergi dalam mewujudkan pendidikan yang bermutu. Kepala sekolah yang bertindak sebagai pengendali mempunyai peran besar yaitu mengendalikan kelulusan sesuai dengan visi yang telah dirumuskan bersama dengan pihak pemangku kepentingan, mengendalikan guru supaya tetap dan makin bermutu serta menjamin proses pembelajaran berlangsung baik dan terukur walau dalam keadaan bagaimanapun seperti dalam pandemi Covid-19 (Sabaruddin, Marzuki, and Khairunnisak 2020). 
Mutu lulusan dapat diwujudkan melalui proses dan manajemen yang baik (Cecep 2017). Mutu lulusan yang baik akan memberikan kepuasan bagi pengguna dan pemangku kepentingan (Daiva, Alifanovienė 2011). Target kinerja segenap warga sekolah adalah mutu lulusan. Mutu bukan hanya nilai dan kelulusan dari ujian namun berbagai aspek lain yang terlihat dari pribadi siswa yang telah lulus (Muzakar 2014). Dalam Undang-Undang sistem pendidikan nasional telah dirumuskan bahwa pendidikan untuk membentuk insan indonesia tidak hanya cerdas, namun memiliki kepribadian yang baik, memiliki kompetensi sehingga membentuk manusia yang beradap dan berbudi mencerminkan ke-Indonesiaan.

Akhir-akhir ini mutu pendidikan Indonesia ramai diperbincangkan. Banyak permasalahan yang harus segera dituntaskan baik dari segi kulaitas akademik maupun kualitas sikap lulusan. Dari perangkingan kelulusan, Indonesia berada di bawah dibandingkan dengan negara-negara tetangga. Persoalan degredasi moral juga kerapa terjadi dikalangan remaja. Seolahseolah sekolah tidak mampu lagi memperbaikinya untuk mendapat lulusan yang berkahlak dan berkompetensi yang unggul. Dalam beberapa penelitian juga membuktikan bahwa guru lebih fokus pada pencapaian akademik dibandingkan dengan penanaman karakter dalam setiap pelajaran (D. Sabaruddin and Rosnidar 2018).

Peran kepala sekolah dalam pengendalian kinerja guru juga sangat berperan terahadap peningkatan mutu pendidikan. Keutamaan dalam penguasaan guru adalah guru harus memiliki kompetensi pedagogi yang baik untuk mengendalikan kelas dalam proses pembelajaran (Dahlan, Sari, and Mansor 2019). Diperkuat oleh hasil penelitian lain yang menunjukkan bahwa motivasi berprestasi, kepuasan kerja, dan manajerial kepala sekolah memiliki korelasi positif yang signifikan terhadap kinerja guru (Sari 2018).

Kepala sekolah juga harus mengendalikan proses pembelajaran yang berlangsung. Kerjasama dengan guru untuk mewujudkan kelas yang nyaman dan menyenagkan dalam pembelajaran sangat diperlukan. Kelas yang nyaman 
dan pembelajaran yang menyenagkan dapat memberikan motivasi belajar bagi siswa (Ramdania, Wulan, and Dwiprabowo 2020). Guru sangat berperan menciptakan suasana belajar bagi siswa, perasaan senang akan berdampak positif dalam peningkatan motivasi belajar siswa dalam kelas (Arianti 2018). Kerjasama antar guru, kepala sekolah, tenaga kependidikan dan orang tua sangat diperlukan untuk mewujudkan suasana pembelajaran yang baik. Masing-masing memiliki peran penting dan tanggungjawab. Perencanaan juga sangat mempengaruhi terhadap suksesnya peningkatan mutu pendidikan melaui sekolah. Yang terpenting dalam manajemen sekolah adalah menyadari bahwa peendidikan adalah untuk semua dan peningkatan karakter adalah tujuan utama (S. Sabaruddin et al. 2020).

Fenomena yang tampak saat ini antara lain peserta didik tidak tertib, sering terlambat sampai di sekolah, kurang disiplin, membuang sampah sembarangan, gairah dan fokus belajar kurang sehingga prestasi belajarnya rendah. Diperparah lagi dengan rendahnya etos kerja guru dan karyawan, rasa kekeluargaan/kebersamaan semakin berkurang. Kepedulian orang tua, komite dan masyarakat terhadap sekolah masih kurang. Ditambah sarana, prasarana, fasilitas dan kelengkapan alat-alat yang ada di sekolah tidak difungsikan/tidak terawat dengan baik untuk mendukung peningkatan prestasi belajar peserta didik.

Permasalahan tersebut tentunya muncul karena manajemen sekolah yang tidak efektif. Manajemen yang tidak efektif mengakibatkan sistem di sekolah tidak berjalan, dan hal ini dapat berakibat sangat fatal. Semua komponen sekolah yang meliputi Sarpras, keuangan, guru dan karyawan di sekolah serta orang tua murid dan masyarakat tidak memiliki daya dukung bagi pencapaian tujuan sekolah, terutama untuk meningkatkan prestasi belajar peserta didik dan sekolah. Oleh karena itu, dirasa perlu untuk menyingkap beberapa hal yang berkaitan dengan manajemen kepala sekolah untuk meningkatkan mutu sekolah. 


\section{B. Metode}

Jenis penelitian ini adalah penelitian tindakan sekolah (PTS). Dengan mengadopsi model Hopkins dan Mc Tagaart (Wayan AS. 2010). Dengan tahapan (1) analisis wacana; (2) rencana tindakan; (3) pelaksanaan tindakan; (4) observasi; dan (5) refleksi. Pengumpulan data dilakukan dengan menggunakan wawancara, observasi, dan diskusi. Analisis data dilakukan dengan mendeskripsikan fenomena yang ditemukan di lapangan secara naratif.

\section{Hasil dan Pembahasan}

\section{Manajemen Sekolah di SD Negeri 6 Langsa}

Hasil penelitian mengungkapkan bahwa Sekolah Dasar (SD) Negeri 6 Langsa belum menerapkan Manajemen Berbasis Sekolah (MBS) secara optimal, hal ini dapat dilihat dari (a) sekolah belum menerapkan manajemen sekolah yang transparan, partisipatif, akuntabel, dan mandiri untuk membangun demokrasi pendidikan; (b) kurangnya partisipasi dan tanggung jawab masyarakat dan orang tua murid dalam membantu/mendukung pengembangan sekolah, perencanaan kegiatan dan anggaran, dan kontrol serta bantuan teknis untuk sekolah; dan (c) kemampuan sumber daya manusia, dalam hal ini guru-guru masih sangat minim khusunya dalam implementasi program MBS.

Selain itu, SD Negeri 6 Langsa juga (d) belum menggunakan sarana dan peralatan yang lengkap untuk mendukung kegiatan belajar-mengajar seperti yang diamanatkan oleh Undang-Undang Nomor 20 Tahun 2003 yang menyatakan bahwa "...Setiap satuan pendidikan formal dan non formal menyediakan sarana dan prasarana yang memenuhi keperluan pendidikan sesuaidengan pertumbuhan dan perkembangan potensi fisik, kecerdasan intelektual, sosial, emosional, dan kejiwaan peserta didik." Penyelenggaraan sekolah tentunya juga membutuhkan pembiayaan. (e) satu-satunya sumber pendanaan di SD Negeri 6 Langsa hanya berasal dari dana Biaya Operasional 
Sekolah (BOS).

Jadi permasalahan manajemen di sini adalah sekolah masih lemah dalam mengimplementasikan MBS, rendahnya partisipasi dan tanggung jawab komponen pendukung pendidikan, dan lemahnya kompetensi sumber daya manusia di sekolah, sarana dan prasarana sekolah yang tidak memadai dan tidak digunakan dengan baik, juga pendanaan sekolah yang hanya bergantung pada dana BOS menjadi kendala besar. Dijelaskan bahwa MBS ini sangat penting dan akan efektif apabila didukung oleh sarana dan prasarana yang memadai (Rafid and Tinus 2019). Penggunaan dana untuk kegiatan di sekolah tidak boleh menyimpang dari juknis pengelolaan dana BOS. Kondisi demikian cukup mempersulit pihak sekolah untuk menggunakan dana sesuai dengan kebutuhan sekolah secara luas. Namun secara umum dana yang ada cukup untuk mendukung terselenggaranya MBS (Windayana 2012).

Untuk mengurangi permasalahan tersebut, maka rencana tindakan yang akan dilakukan adalah dengan cara meningkatkan partisipasi, menampung ide dan kritik serta solusi yang diberikan. Prosedur yang dilakukan membuat program antara lain tentang (a) sosialisasi kepada guru dan staff melalui rapat rutin yang dilaksanakan setiap sabtu; (b) melakukan sosialisasi kepada siswa pada saat pelaksanaan upacara dan kegiatan rutin lainnya; (c) memberikan sosialisasi kepada masyarakat dan stakeholder secara langsung setiap ada kegiatan atau pertemuan; (d) menyiapkan instrumen/sarana pendukung pelaksanaan Manajemen PAKIS berupa Kotak Aspirasi PAKIS dan Agenda Rapat.

\section{Proses Pelaksanaan}

Adapun tahapan proses pelaksanaan manajemen berbasis sekolah PAKIS (Partisipasi, Aspirasi, Kritik, Ide, dan Saran) melalui kotak aspirasi adalah dengan membuat kotak aspirasi untuk siswa, warga sekolah dan masyarakat termasuk Dinas Pendidikan, pengawas sekolah, lembaga swadaya masyarakat, guru, dan tenaga administrasi sekolah, yang selanjutnya dibahas bersama pada pelaksanaan rapat rutin mingguan. 
Hasil pengumpulan PAKIS yang diperoleh dalam kurun waktu tertentu, satu minggu atau satu bulan direkapitulasi dan dipilah dengan kategori informasi sebagai berikut:

a) Sanjungan, pujian, dan kepuasan

b) Usulan atau ide untuk pengembangan sekolah

c) Kritik dan solusi

d) Keluhan dan pengaduan

e) Tidak dapat dikategorikan karena hanya bersifat iseng dan tidak dapat dipertanggungjawabkan

Upaya berikutnya yang dilakukan adalah dengan menjalin kerjasama dengan berbagai pihak seperti:

1) Polsek Langsa Kota bertujuan untuk memberikan pelayanan keamanan;

2) Dinas Lingkungan Hidup untuk meningkatkan kebersihan;

3) UPTD Puskesmas Langsa Kota untuk memberikan pelayanan kesehatan;

4) Museum Kota Langsa untuk memberikan informasi mengenai sejarah;

5) PBSI cabang Kota Langsa untuk memberikan layanan ekstrakurikuler kepada peserta didik;

6) BNN Kota Langsa untuk mengatasi dan mengurangi tingkat penggunaan Narkoba;

7) BPBD Kota Langsa untuk pelayanan penanggunglangan bencana dan siaga bencana;

8) Dinas Perpustakaan dan Kearsipan untuk pelayanan pemanfaatan perpustakaan

9) Desa Gampong Jawa untuk meningkatkan pelayanan kemasyarakatan

10)Komite Sekolah untuk menstimulus pelayanan warga sekolah

\section{Hasil Pelaksanaan}

Hasil yang diperoleh selama pelaksanaan manajemen PAKIS bukan merupakan hasil akhir namun merupakan proses perkembangan dan kemajuan yang terus berjalan secara berkesinambungan. Namun dari 
perbandingan antara kondisi awal dan kondisi akhir dalam kurun waktu satu setengah tahun berjalan dapat diperoleh kemajuan yang cukup signifikan. Berdasarkan hasil rekapitulasi PAKIS dari berbagai sumber dapat dijabarkan usulan, permasalahan, solusi, dan tindak lanjut serta hasil yang telah didapatkan sebagai berikut:

Tabel 1. Kegiatan Kesiswaan

\begin{tabular}{|c|c|}
\hline Aspek & Data \\
\hline \multirow[t]{3}{*}{ PAKIS } & a) Penambahan dan pertandingan ekstrakurikuler \\
\hline & $\begin{array}{l}\text { b) Pergantian pembina/pelatih ekstrakurikuler yang tidak } \\
\text { aktif }\end{array}$ \\
\hline & c) Penambahan pembina Pramuka Putri \\
\hline \multirow[t]{4}{*}{ Tindak Lanjut } & $\begin{array}{l}\text { a) Menambah dan mengaktifkan kegiatan ekstrakurikule, } \\
\text { OSN, FLS2N, dan O2SN; }\end{array}$ \\
\hline & $\begin{array}{l}\text { b) Mengikutsertakan siswa dalam perlombaan dan } \\
\text { pertandingan tingkat kota, provinsi, atau nasional; }\end{array}$ \\
\hline & c) Mengangkat pembina ekstrakurikuler yang baru \\
\hline & d) Mengangkat pembina Pramuka putri. \\
\hline \multirow[t]{3}{*}{ Hasil } & a) Ekstrakurikuler siswa makin banyak dan beragam; \\
\hline & b) Siswa berhasil menjuarai pertandingan dan perlombaan; \\
\hline & c) Terpilihnya pembina yang baru \\
\hline \multirow[t]{3}{*}{ Dampak } & $\begin{array}{l}\text { a) Beragamnya kegiatan ekskul yang diselenggarakan } \\
\text { menampung lebih banyak minat dan bakat peserta didik }\end{array}$ \\
\hline & $\begin{array}{l}\text { b) Berbagai prestasi yang diperoleh siswa dalam mengikuti } \\
\text { kegiatan meningkatkan motivasi dan semangat siswa } \\
\text { dalam mengikuti ekskul }\end{array}$ \\
\hline & $\begin{array}{l}\text { c) Dengan pengangkatan dan pergantian pembina, kegiatan } \\
\text { ekstrakurikuler berjalan lebih aktif dan efektif }\end{array}$ \\
\hline
\end{tabular}

Tabel 2. Kegiatan Belajar Mengajar

\begin{tabular}{l|l}
\hline \multicolumn{1}{c|}{ Aspek } & \multicolumn{1}{c}{ Data } \\
\hline PAKIS & a) Guru memberikan tugas kepada siswa dan jarang \\
& menjelaskan \\
Tindak Lanjut & a) \\
& Gemberikan teguran dan pembinaan kepada guru yang \\
& b) Mengadakan pembinaan pada guru; \\
& c) Melaksanakan sosialisasi dan bimbingan mengajar serta \\
Hasil & a) Kedisiplinan guru dalam melaksanakan KBM meningkat; \\
Dampak & b) Alat peraga pembelajaran lebih lengkap \\
& Dengan telah tersedianya kelengkapan alat peraga PBM dapat \\
& berjalan lebih efektif
\end{tabular}


Tabel 3. Sarana dan Prasarana Sekolah

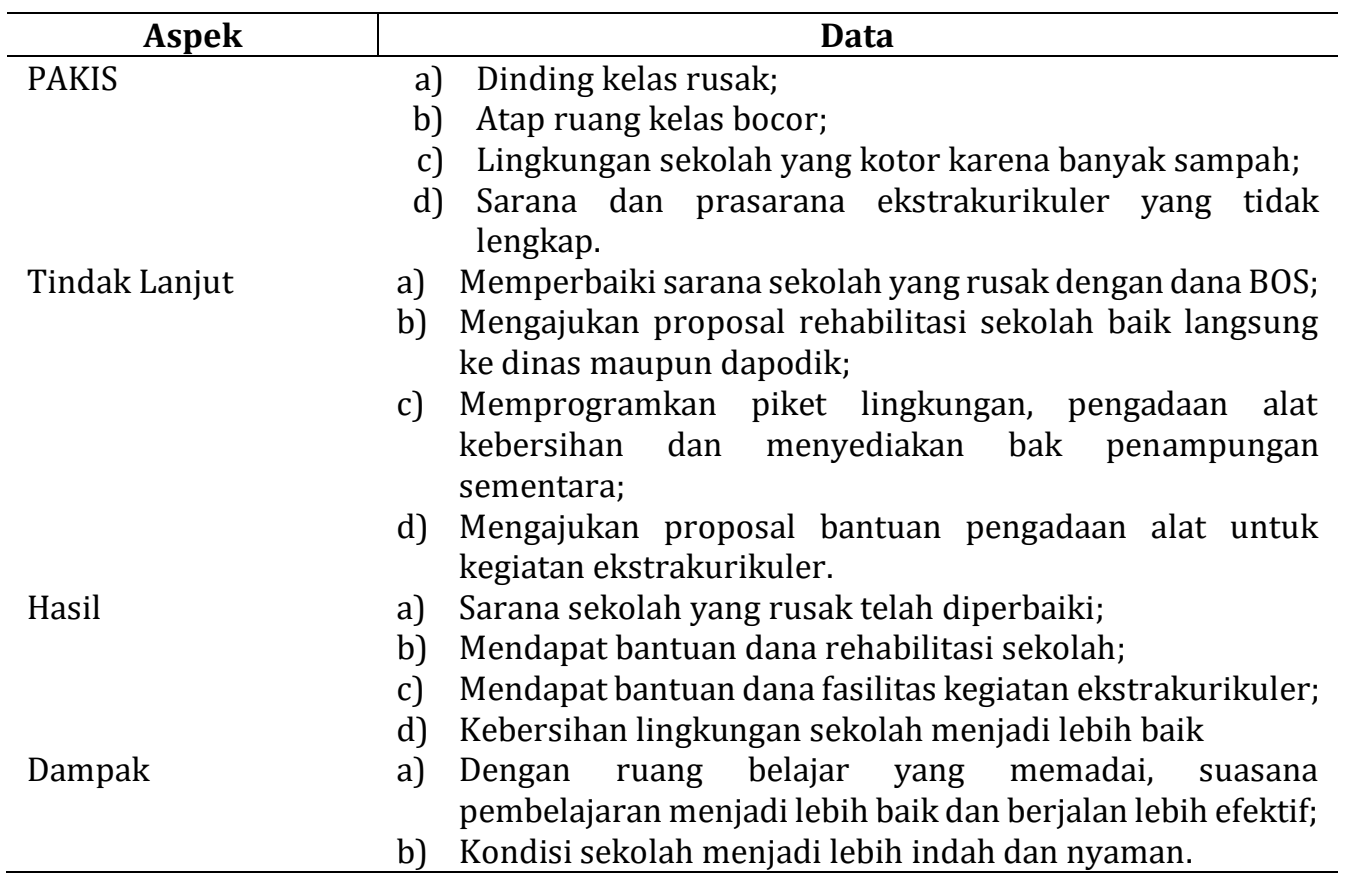

\section{Tabel 4. Manajemen Sekolah}

\begin{tabular}{|c|c|c|}
\hline Aspek & & Data \\
\hline \multirow[t]{8}{*}{ PAKIS } & a) & $\begin{array}{l}\text { Kedisiplinan guru sangat kurang, sering datang terlambat, } \\
\text { masuk ke dalam kelas terlambat; }\end{array}$ \\
\hline & b) & $\begin{array}{l}\text { Administrasi mengajar guru sering tidak dibuat dan tidak } \\
\text { lengkap; }\end{array}$ \\
\hline & c) & $\begin{array}{l}\text { Hubungan sosial guru dan staf masih rendah dan kurang } \\
\text { terkoordinasi; }\end{array}$ \\
\hline & d) & $\begin{array}{l}\text { Aktivitas dan frekuensi guru dalam mengikuti kegiatan } \\
\text { perlombaan masih rendah; }\end{array}$ \\
\hline & e) & $\begin{array}{l}\text { Sopan dan santun siswa terhadap guru dan sesama teman } \\
\text { masih rendah }\end{array}$ \\
\hline & f) & $\begin{array}{l}\text { Program kerja sekolah, RKS dan RKAS belum disusun } \\
\text { secara prosedural; }\end{array}$ \\
\hline & g) & $\begin{array}{l}\text { Dokumen kurikulum belum disusun secara prosedural dan } \\
\text { belum didokumentasikan dan diarsipkan secara lengkap } \\
\text { dan teratur; }\end{array}$ \\
\hline & h) & $\begin{array}{l}\text { Program dan dokumen perencanaan dan pelaksanaan } \\
\text { kegiatan sekolah belum berjalan dan tersusun dengan baik }\end{array}$ \\
\hline \multirow[t]{4}{*}{ Tindak Lanjut } & a) & $\begin{array}{l}\text { Memberikan pembinaan, nasihat, dan teguran kepada } \\
\text { guru untuk melaksanakan tugas dengan baik dalam setiap } \\
\text { rapat rutin; }\end{array}$ \\
\hline & b) & $\begin{array}{l}\text { Membuat kesepakatan untuk kegiatan sosial dan } \\
\text { kemasyarakatan; }\end{array}$ \\
\hline & c) & $\begin{array}{l}\text { Membuat dan menerapkan peraturan tata tertib sekolah } \\
\text { dengan lebih tegas dan menguatkan pendidikan karakter } \\
\text { melalui kegiatan rutin sekolah; }\end{array}$ \\
\hline & d) & $\begin{array}{l}\text { Pembuatan dan penyusunan program kerja dan kurikulum } \\
\text { sekolah melalui kegiatan sekolah model. }\end{array}$ \\
\hline
\end{tabular}




\begin{tabular}{l|l}
\hline \multicolumn{1}{c|}{ Aspek } & \multicolumn{1}{c}{ Data } \\
\hline Hasil & a) $\begin{array}{l}\text { Kedisiplinan, kinerja dan hubungan sosial kekeluargaan } \\
\text { guru meningkat, dibuktikan dari hasil pengamatan, }\end{array}$ \\
& supervisi pelaksanaan KBM dan suasana kekeluargaan di \\
& sekolah; \\
& b) $\begin{array}{l}\text { Kedisiplinan siswa meningkat, dibuktikan dengan } \\
\text { keaktifan siswa dalam belajar; }\end{array}$ \\
& c) $\begin{array}{l}\text { Program kerja dan dokumen kurikulum sekolah telah } \\
\text { tersedia dan tersusun dengan baik }\end{array}$ \\
Iklim pembelajaran dan juga sekolah menjadi semakin tertata \\
Dampak
\end{tabular}

Dari uraian hasil di atas, perkembangan sekolah menuju ke sekolah yang berkualitas sudah mulai terwujud dan sudah dirasakan dampaknya oleh komunitas sekolah. namun hal itu masih perlu dikembangkan dan membutuhkan proses yang akan memakan waktu, sumber daya dan kerjasama dari semua pihak yang berperan baik secara langsung maupun tidak langsung untuk mewujudkan SD Negeri 6 Langsa menjadi sekolah yang unggul.

\section{4) Evaluasi dan Monitoring}

Pada Prinsipnya, evaluasi monitoring dilakukan dengan tujuan untuk mengetahui apakah manajemen PAKIS berhasil mencapai target yang telah ditentukan, maka harus dilakukan pemantauan untuk mengukur kemajuan yang diharapkan. Proses evaluasi dan monitoring yang dilakukan terus menerus akan membantu memastikan bahwa kegiatan ini tetap berkelanjutan. Pelaksanaan evaluasi dan monitoring dapat dilakukan sendiri oleh pihak sekolah.

Evaluasi dan monitoring untuk ketercapaian rencana aksi PAKIS dapat dilaksanakan oleh sekolah dengan menggunakan kuesioner dan survei untuk mengumpulkan data kemajuan kegiatan dengan melibatkan siswa dalam bentuk antara lain :

a) Untuk melihat sejauh mana pengaruh kegiatan PAKIS 
b) Mendokumentasikan setiap tahap kegiatan (sebelum, selama, dan setelah) dalam bentuk dokumentasi untuk membandingkan perubahan yang terjadi di sekolah.

Untuk mengukur keberhasilan program yang sudah ditetapkan kepala sekolah membentuk Tim Audit Internal yang bertugas melakukan monitoring dan evaluasi terhadap pelaksanaan PAKIS dalam membentuk keperdulian warga sekolah di SD Negeri 6 Langsa yang sudah ditetapkan bersama. Audit pelaksanaan pemenuhan mutu atau disebut juga dengan monitoring dan evaluasi (monev) dilaksanakan untuk memastikan bahwa pelaksanaan pemenuhan mutu sesuai dengan rencana yang telah dibuat. Monitoring dilaksanakan bersama dengan proses pelaksanaan pemenuhan mutu. Hasilnya lalu dievaluasi diakhir kegiatan untuk dijadikan dasar pengambilan keputusan atau penyusunan program tindak lanjut pasca monev. Adapun strategi pemenuhan mutu yang baru dilakukan jika kegiatan pemenuhan mutu yang lama telah selesa dilaksanakan.

\section{5) Tindak Lanjut}

Inovasi dan Perbaikan Program dan tindakan yang telah disusun dan dilaksanakan.

1. Informasi berupa sanjungan, pujian, dan kepuasan dikelompokkan dalam satu kategori dengan tanpa tindak lanjut kegiatan hanya dijadikan referensi sebagai motivasi untuk melaksanakan kegiatan selanjutnya.

2. Informasi berupa usulan atau ide yang dapat langsung ditindaklanjuti akan segera dilaksanakan. Sedangkan usulan atau ide yang tidak dapat langsung ditindaklanjuti akan dijadikan referensi untuk penyusunan program sekolah selanjutnya.

3. Informasi berupa kritik dan solusi yang diberikan dikelompokkan untuk sekolah yang memungkinkan dan dijadikan bahan intropeksi bagi manajemen sekolah.

4. Informasi berupa keluhan dan pengaduan dikelompokkan untuk dapat 
diklarifikasi dan dicarikan solusi untuk pemecahannya.

5. Informasi yang tidak dapat dikategorikan karena hanya bersifat iseng dan tidak dapat dipertanggungjawabkan dipisahkan untuk kemudian dimusnahkan.

Tindak lanjut hasil PAKIS ada yang langsung ditangani kepala sekolah namun sebagian juga ditindaklanjuti oleh wakil kepala sekolah, wali kelas, guru, tenaga administrasi sekolah, dan tenaga kependidikan lainnya.

\section{Kesimpulan}

Berdasarkan hasil dan pembahasan penelitian ini dapat disimpulkan sebagai berikut:

1. Pelaksanaan mananemen PAKIS di SD Negeri 6 Kota Langsa berjalan dengan baik

2. Dampak yang dirasakan dari penerapan manajemen PAKIS dapat meningkatkan prestasi sekolah di SD Negeri 6 Langsa di antaranya meningkatnya prestasi siswa baik dalam bidang akademik maupun non akademik, prestasi guru, prestasi sekolah maupun prestasi kepala sekolah.

3. Faktor pendukung pada penerapan manajemen berbasis sekolah PAKIS dalam meningkatkan prestasi sekolah diantaranya dukungan warga sekolah, dukungan masyarakat dan dukungan lembaga lain

Pada hal ini dapat diberikan beberapa rekomendasi terkait implementasi manajemen PAKIS, yaitu:

1. Pihak sekolah diharapkan terus memberikan kesempatan kepada masyarakat untuk berpartisipasi dalam membantu meningkatkan kualitas pendidikan di sekolah.

2. Guru harus meningkatkan partisipasi dalam pelaksanaan MBS di SD Negeri 6 Langsa agar mutu sekolah lebihmeningkat.

3. Kepala Dinas sebagai pengambil kebijakan memberikan kesempatan merata kepada seluruh kepala sekolah untuk mengikuti pendidikan dan pelatihan. 
4. Penerapan MBS supaya betul-betul dilaksanakan, agar proses yang diinginkan dapat benar-benar tercapai.

\section{DAFTAR PUSTAKA}

Adam, Firman, Dedy Achmad Kuriady, and Aan Komariah. 2018. "STRATEGI MANAJERIAL DAN CAPAIAN MUTU SEKOLAH.” Educational Administration Research and Review 2(1).

Alawiyah, Faridah. 2017. "National Standards of Primary and Secondary Education.” Aspirasi 8(1): 81-92.

Arianti. 2018. "Peranan Guru Dalam Proses Pembelajaran." Didaktika Jurnal Kependidikan 12(2): 117-34.

Cecep, Taryaman. 2017. "Pengaruh Manajemen Pembelajaran Terhadap Kinerja Guru Dalam Mewujudkan Prestasi Belajar Siswa." Jurnal Pendidikan Universitas Garut 11(1): 1-8.

Dahlan, Sabaruddin, Rita Sari, and Rosnidar Mansor. 2019. "Kompetensi Pedagogik: Sebuah Tinjauan Tentang Internalisasi Nilai-Nilai Karakter Pada Pembelajaran Matematika SD." Suska Journal of Mathematics Education 5(1): 9. http://ejournal.uinsuska.ac.id/index.php/SJME/article/view/6318/4166.

Daiva, Alifanovienè, Asta Vaitkevičienè. 2011. “Development of Students' Competences in Special Education Studies, Applying the Description of the Teacher's Professional Competence and Research on Students' Opinion." Teacher Education 17(17): 87-104.

Muzakar. 2014. "Kinerja Kepala Sekolah Dalam Meningkatkan Mutu Lulusan Pada Madrasah Tsanawiyah Negeri Meureubo." Jurnal Ilmiah Islam FUTURA 14(1): 110-33.

Nurkuntari, Yuni. 2016. "Pengaruh Manajemen Sekolah Terhadap Mutu Pendidikan Sekolah Menengah Atas Di Kota Semarang." VALUE ADDED / MAJALAH EKONOMI DAN BISNIS 12(2): 86-100.

Puspitasari, Yeni, Tobari Tobari, and Nila Kesumawati. 2020. "Pengaruh Manajemen Kepala Sekolah Dan Profesionalisme Guru Terhadap Kinerja Guru." JMKSP (Jurnal Manajemen, Kepemimpinan, dan Supervisi Pendidikan) 6(1): 2021.

Rafid, Rahmad, and Agus Tinus. 2019. "Kinerja Kepala Sekolah Dalam Meningkatkan Mutu Tenaga Pendidik Di Sekolah Menengah Atas Negeri 1 Latambaga." Jurnal Akuntabilitas Manajemen Pendidikan 7(2): 188-98.

Ramdania, Vina Nur, Sarah Wulan, and Risky Dwiprabowo. 2020. "Upaya Meningkatkan Motivasi Belajar Siswa Dalam Mata Pelajaran Matematika Dengan Strategi Pembelajaran Aktif Kreatif Efektif Dan Menyenangkan." Prosiding Seminar Nasional Pendidikan STKIP Kusuma Negara II II(1): 78-85.

Sabaruddin, Dahlan, and Mansor Rosnidar. 2018. "Parents' Involvement in Improving Character of Children through Mathematics Learning." 
Peuradeun 6(1): 41-50.

Sabaruddin, Marzuki, and Khairunnisak. 2020. "Pandemic Covid-19: The Opportunities and Challenges to Using ICT in Mathematics Learning." IJEBD International Journal Of Entrepreneurship And Business Development eISSN 2597-4785 pISSN 2597-4750 3(4): 409-14.

Sabaruddin, S, R Mansor, I Rusmar, and F Husna. 2020. "Student with Special Needs and Mathematics Learning: A Case Study of an Autistic Student." JRAMathEdu (Journal of Research and Advances in Mathematics Education) 5(3): 317-30.

Sari, Rita. 2018. "Motivasi Berprestasi, Kepuasan Kerja Dan Manajerial Kepala Sekolah Serta Dampaknya Terhadap Kinerja Guru." Journal of Education, Humaniora and Social Sciences (JEHSS) 1(1): 16-19.

Wayan AS., I. 2010. Akuntabilitas Kinerja Kepala Sekolah Dan Penelitian Tindakan Sekolah Untuk Kepala Sekolah Dalam Rangka Peningkatan Mutu Pembelajaran Serta Bahan Belajar Mandiri Dimensi Kompetisi Kepala Sekolah. Jakarta: Az-Zahra Books.

Windayana, Husain. 2012. 4 EduHumaniora | Jurnal Pendidikan Dasar Kampus Cibiru Penelitian Tindakan Sekolah. 